\title{
An Advocacy Approach to Scaling up Involvement of Men in Maternal and Neonatal Child Health: A Model of Meteitei Sub-County of Kenya
}

\author{
Simon Macharia Kamau ${ }^{*}$, Leah Chepkurui Ng'eno ${ }^{2}$, Lily Chepketer Ng'eno ${ }^{1}$ \\ ${ }^{1}$ Department of Nursing Sciences, University of Kabianga, Kericho, Kenya \\ ${ }^{2}$ Meteitei Sub-County Hospital Nandi, Nandi County, Kenya \\ Email: *smacharia@kabianga.ac.ke,ngenoleah338@gmail.com, lilyot2008@gmail.com
}

How to cite this paper: Kamau, S.M., Ng'eno, L.C. and Ng'eno, L.C. (2017) An Advocacy Approach to Scaling up Involvement of Men in Maternal and Neonatal Child Health: A Model of Meteitei SubCounty of Kenya. Open Access Library Journal, 4: e3846.

https://doi.org/10.4236/oalib.1103846

Received: July 25, 2017

Accepted: August 13, 2017

Published: August 16, 2017

Copyright $\odot 2017$ by authors and Open Access Library Inc.

This work is licensed under the Creative Commons Attribution International License (CC BY 4.0).

http://creativecommons.org/licenses/by/4.0/

\section{(c) (i) Open Access}

\begin{abstract}
Male partners would tend to isolate themselves when it reaches a time when a woman is in the perinatal period. With men incorporated Meteitei region showcased that the death of another mother neonate or child was one too many, and was not excusable. Ultimately it should be possible to eliminate mother to child transmission of HIV. Method: This study employed advocacy approach. It is cognizant of the fact that the founder of modern nursing Florence Nightingale part of her success was related to advocacy and activism. In advocacy, the nurse leader should anticipate some controversies, and be ready to make rebuttals. It makes a case for male involvement in Maternal and Neonatal Child Health $(\mathrm{MNCH})$ and also covers some contentious issues on the same as counter arguments in point forms and text boxes. The policy issue was a way of possibly scaling up the success story of Meteitei region Nandi County's Chama cha Wazee male champions to the national level. Outcomes: This compilation was a modification to a policy issue entitled: Proposed Policy on Involvement of Men in Maternal and Neonatal Child Health which was submitted to The Senate alongside others in response to a requirement of public hearings. Hopefully, its due merits were considered. Advocacy tools like policy issue have an invaluable place in the future-now health care in nursing and midwifery.
\end{abstract}

\section{Subject Areas}

Health Policy, Nursing, Public Health

\section{Keywords}

Male Involvement, Maternal Neonatal Child Health, Advocacy, Male 
Champions, Policy Issue

\section{Background of Maternal Neonatal System}

Issues of the new-born cannot be addressed separately as they were intrinsically entwined with pregnancy, labour, delivery and postpartum care. Thus there was a need to integrate the maternal, neonatal and child Health (MNCH). Kenya made significant strides in reduction of mortality rates in maternal, neonatal and children in the last five years but there were still concerns emanating from the results of the Kenya Demographic Health Surveys (KDHS). However, maternal and newborn health indicators in Kenya had generally shown very marginal improvement over the years. Infant, under five mortality, declined from 74 to 52 per 1000 and infant mortality from 52 to 39 per 1000 compared to 2009. This was according to KDHS released in January 2016. It also indicated a $96 \%$ of women had a live birth in the last five years. The maternal mortality dropped from $488 / 100,000$ in 2009 to $362 / 100,000$ in 2016 . 58\% of women attended 4 or more antenatal visits during pregnancy up from $47 \%$. (However, the Meteitei case study done in 2015 utilized the 2013 statistics).

There was a need for nurses and midwives to get men to buy into $\mathrm{MNCH}$ as key stakeholders to resource mobilize for identified priority actions (as will be described in the article). The main purpose of involving males is to improve maternal, child and newborn survival. Home grown solutions like Meteitei's case would in some way show case that with support such efforts could be customized across the country

However, this needed a well-coordinated front. By sending a policy issue to The Senate, the upper house followed with a petition to advocate for laws and policies to scale up male involvement in $\mathrm{MNCH}$. Coincidentally, The Senate had sent out a requirement for public hearing and memorandum in a related area. This article is largely an amplified version of this attempt; the response so far is encouraging.

\subsection{Why an Advocacy Approach}

An advocacy approach involves influencing powerful decision makers to bring about change. It can be a long process because it often involves changing people's views. According to [1], to change communities from being passive participants to active participants in the priority setting process, there was a need for them to be empowered to demand for publicity, appeal, relevance and strong leadership in the priority setting process. Thus, redefining the appeals mechanism and expanding the opportunities for the communities to contribute relevant considerations to each decision and specifying the ground for appeal would help improve the quality of the decision-making process.

Advocacy plays a significant role in the modern politics of inclusion. It seeks 
to cause benefit (usually long term) to be accrued to individuals and groups where possibly none would have been in the absence of the advocacy effort. It had been shown to bring to or restore a sense of significance or relevance to an issue that was overlooked (Wikipedia). It was also tied to a method of problem solving or resolution and driving systems change. Professionals, associations etc. have a key role of taking up the role of advocacy for their own cause or that of others (usually less powerful or less fortunate) because they can generate energy and flow in articulating issues.

To underscore the invaluable impact of advocacy work [2] [3] cited some work from a community in Uganda. One government official said, "Before they approached us, I didn't really think much of these communities. But since they advocated and engaged with us, we can now see how we can work with them". Members of the community on the other hand “...if we don't get a response from the government, we will keep demanding it". In other words, the process of advocacy is valuable, whatever the result. Joanna Watson compiled some advocacy toolkits worth checking out [4], together with [5].

Advocacy in primary caring promotes exposing, provoking, and unbalancing the social power that maintains people in a state of disease, while simultaneously nurturing caring [6]. No one is going to accept your opinions and reasoning just because you say so, you will need proof, organized proof and attention to detail. Therefore, the nurse leader should be prepared to argue for, take a position that needs to be defended, as well as be ready for objections to those positions.

Florence Nightingale the founder of modern nursing left a legacy connecting caring with advocacy [7]. She wrote that "It may seem a strange principle to enunciate as the very first requirement in a hospital that it should do the sick no harm. It is quite necessary, nevertheless, to lay down such a principle" [8] [9].

Nightingale argued using statistics, to prove that decreasing mortality would cost less money... for patients to heal translating into what we would now consider as evidence-based practice [10]. She ably plotted a polar pie chart on the Crimean battle hospitals mortalities significant decline (from $42 \%$ to $2 \%$ ) as result of her interventions (mainly by improved hygiene, and advocacy by calling upon the British Sanitary Commission).

When she was nearing the end of her life, Florence Nightingale said: "May we hope that when we are all dead and gone, leaders will arise who have been personally experienced in the hard, practical work, the difficulties and the joys of organizing nursing reforms, and who will lead far beyond anything we have done". Further "All the results of good nursing may be spoiled or utterly negatived by one defect, viz.: in petty management, or in other words, by not knowing how to manage that what you do when you are there, shall be done when you are not there". An all time work, "Notes on Nursing" excerpts by Florence Nigtingale.

Some of the ways that nurses could get involved in advocacy included: writing a policy issue, policy brief, sending petitions, memoranda to-Parliament, The Senate, County Assembly etc. The following is a modification from a policy issue 
originally done by SMK (a co-author of this article). A policy issue is generally a much smaller document.

\subsection{Policy Issue}

The following policy issue dated 25/07/2015 was submitted to Clerk of the Senate, Kenya's Eleventh Parliament, The Senate Standing Committee on Health. Email: senatebills@parliament.go.ke

Subject: Cancer Prevention\& Control (Amendment) Bill, 2015; HIV AIDS Prevention, (Amendment) Bill, 2015; National Insurance Fund (Amendment) Bill, 2015. Response to Requirement of Public Hearings/Receipt of Memoranda: Proposed Policy on Involvement of Men in Maternal and Neonatal Child Health, HIVI AIDS Prevention, National Insurance Fund and Cancer Prevention \& Control in Kenya.

\section{Involvement of Men in Maternal and Neonatal Child Health Kenya}

Description of the issue addressed by the policy

The scenario: Within the rural context, not delivering at the health facility may mean the difference between life and death for both the mother and the neonate. Men have tended to keep off "the women business" only to be called in when the attending women have tried everything and anything conceivable to help the woman in labour. Involvement of the man was key for doing checks, arising needs, rearranging priorities to meet the changing demands of care or for a referral. This is Meteitei, a mountainous region of Tenderet-Nandi escarpment, Rift Valley Province of Kenya http://www.ikimap.com/map/administrative-area-meteitei-kenya. Here, about 92\% of women attended ANC at least once during pregnancy but skilled attendant delivery (SAD) was $6.8 \%$, compared to the national average SAD of $44 \%$ [11]. It had Maternal Mortality Rate (MMR) of 500 per 100,000 by 2013 report.

Most maternal and neonatal deaths are caused by a few conditions, most of which are preventable with available interventions integrally related to the availability and quality of essential and emergency child birth services. Effective interventions to reduce maternal deaths, stillbirths and newborn and child deaths reach less than half the pregnant women, mothers, newborns and children who need them.

Problem statement. You are a policy analyst/developer. Your team has been asked to develop a policy to supplement government effort to reduce maternal infant mortality by working with male champions in Maternal Neonatal Child Health (MNCH).

During a presentation by Dr. Jean Kagia, Obstetrician Gynaecologist from Kenya presented on improving access to maternal health in Kenya to International Symposium on Maternal Health Dublin, Ireland, 2012 (take help of a tu- 
torial on YouTube available on

https://www.youtube.com/watch?v=aFghLVWyFTw.)

The huge difference in the risk of maternal deaths between the developing and developed countries was thought to be due to differences in access and use of maternal health care services [15]. "There are virtually no children born with HIV in the US, Europe, or other western countries, the vast majority of affected children are born in sub-Saharan Africa"-Born free

One specific policy-relevant problem that was discussed as part of the meeting was a most urgent need to involve men in maternal and neonatal child health. This called for developing a policy which would have a multifaceted approach:

* Reduction of maternal \& child mortality and morbidity,

* Elimination of mother to child transmission of HIV and

*Increase uptake of family planning.

Counterargument. Some other people might have picked it up and it's already happening. Or who is behind it, it's a foreign idea, a foreign donor perhaps?

\subsection{Background}

Maternal mortality rates (MMR) MMR levels in Kenya have remained unacceptably high at 488 per 100,000 live births (approximately 7700 women annually), with some regions like Lamu County reporting MMRs of over 1000/ 100,000 live births. These are disturbing facts. In the words of AMREF [12], Lamu needs us to do more. These figures translate to a lifetime risk for maternal death in Kenya of 1 in 39. When this was compared to developed nations such as North America, MMR was 11/100,000 live births with a lifetime risk for maternal death of 1 in 3,800 [14] [16] [17].

Many new-borns died in Kenya in the first month of life (26 per 1000 live births). In 2012, 100,000 died before their 1st birthday. Everyday 15 mothers and over 290 children below the age of 5 died largely from childhood preventable diseases, pregnancy, birth complications and HIV and AIDS [18] [19].

The three delays

- Ask men to help us deal with the 3 delays decisively; these delays contribute to maternal/neonatal morbidity and mortality:

1. Delay in deciding to seek appropriate care. This could be due to: sociocultural barriers, failure to recognize danger signs, failure to perceive severity of illness, and cost considerations

2. Delay in reaching an appropriate health care facility. This is due to long distance to a facility, poor condition of roads - rocky steep, rivers overflow during the rainy season, lack of transportation and cost considerations

3. Delay in receiving adequate emergency care at the facility. This may be due to: Shortage of staff, supplies, and basic equipment; unskilled personnel, user fees among others 
Counterargument: Some opposed say our context is different and figures can lie, that things have improved in last 4 years.

${ }^{*}$ Nationally the prevalence HIV was $6.1 \%$ (women $6.9 \%$ and $4.4 \%$ men) [20]. According to Born Free [21], more than $90 \%$ of new HIV infections in children resulted from mother to child transmission during pregnancy, childbirth, or breastfeeding. It has been seen that it is possible for some countries to significantly accelerate their paths toward virtual elimination [22].

Counterargument: Achieving a beyond zero figure needs to be looked at as long term goal not possible in near future.

\subsection{Meteitei Case Study}

Between Dec. 2011-Sept. 2012 only 5 (0.5\%) out of 1063 PMCT-tested women had their male partners receive HIV counseling and testing (Table 1 shows the target population).

- Between Dec. 2012-Sept. 2013, 181 (17\%) out of 1060 PMCT-tested women had their male partners receive HIV counseling and testing. This was a great improvement.

The rest $(1060$ minus $181=879)$ the partner did not come, only the women were available for counseling \& testing. Only one couple who tested HIV+ was linked to care and treatment.

Some of the factors that might have contributed to high maternal child mortality in rural Meteitei include:

- Poor sensitization of women to the importance of delivery by a skilled attendant, the highly valued social role played by traditional birth attendants (TBAs) in communities,

- The perception that the health facility as a harsh setting for childbirth.

- Other important barriers include lack of means of transport to the health facilities, hostile terrain, cost of transport and delivery,

- Fast progression of labour,

- Some women did not think facility attendance was necessary due to previous uneventful home delivery and therefore prefer home delivery.

Cap 253 Reproductive Health Bill. The Bill also seeks to deal with the issue ot inadequate facilities at county government hospitals, especially in terms ot emergency services including but not limited to ambulance services and equipment for intensive care services and gynaecological services as well. "maternal care" includes health care of a woman during pregnancy, child health and forty two days after childbirth.

Counterargument: the bill was sponsored by a woman parliamentarian, it might have many "anti-men" provisions, requires a lot of amendments before it can become law.

- There was the need to fast-track legislation focussing on $\mathrm{MNCH}$ matters. By 
Table 1. Meteitei catchment population projections for 2014 Maternal Child Health \& Reproductive Health (MCH/RH) Clinic.

$\begin{array}{cc}\text { Population } & \text { No. } \\ \text { Catchment population } & 25,288 \\ \text { Target Population }<1 \text { year old } & 966 \\ \text { Monthly target } & 80 \\ \text { Adolescents } & 3783 \\ \text { Women of reproductive age } & 6679 \\ \text { Pregnant women } & 1,138 \\ \text { Children }<5 \text { years old } & 4552\end{array}$

Source-Health records Meteitei SD Hospital, 2013.

June 2016, it was reported that only 5 of the many bills originating from The Senate had gone through Parliament to reach the President's signature into law in the last 3 years. It might be possible that The Reproductive Health Care Bill 2014 could be one of the many bills sequestering in parliament.

Counterargument. We continue to witness supremacy battles between The Senate and The National Assembly (parliament).

\section{Rationale}

The rationales for emphasizing male men involvement in $\mathrm{MNCH}$ rests in its benefits in preventing maternal mortality (MMR) and neonatal infant child mortality include:

- Identifying barriers that hinder the uptake of ANC, delivery in hospital, and family planning services from a male perspective. Considering men been have side-lined for so long and we all know that they play a huge role in determining if the mothers come to the clinic or not.

- It is especially important to understand ways to get male involvement in helping to achieve zero mother to child HIV transmission, improve the effectiveness of PMTCT service delivery models.

- Men control about $70 \%$ of the family expenditure with women and other members controlling about $25 \%$ as cited in [13] above. In our low-income setting, men are hardly involved in reproductive health issues.

- Men are gate keepers of culture and society values, some of which still contain and accept several harmful practices that have very negative effects on women and their reproductive health rights. These practices include early or child marriages, female genital cutting or mutilation and nutritional taboos that affect the health of girls and women. Counterargument: women are their own worst enemies. 
- Reproductive health services are important entry points for most HIV and AIDS services, such as prevention of mother-to-child transmission (PMTCT), voluntary counseling and testing (VCT) for HIV and AIDS and antiretroviral therapy (ART) interventions as was cited in [19] above.

Counterargument: There were many claims trying to ascertain why HIV/ AIDS prevalence was on the rise especially to married couples. None seems to be coming out clearly.

Men entry into the MNCH system

-Home (husband, spouse, partner, brother, teenage/young adult, boy child). Figure 1 below shows an example in a family setting.

-Community (friend, neighbour, $\mathrm{CHV}, \mathrm{CHW}$, church, schools, place of work, farms, CBOs e.g. Chama cha Wazee, Manpower)

-Health facility (Maternity, PMCT, VCT, MCNH clinic)

-Sub-County (advocacy, leaders), NGOs

-County (advocacy, leaders, resource allocation, ordinances making, supporting affirmative action of $2 / 3$ gender representation, make maternal health a standing agenda)

-National (advocacy, legislation, supporting the affirmative action of $2 / 3$ gender representation, a commitment of resources for maternal and new-born health, make maternal health a standing agenda).

--Sponsor motions to improve access to maternal neonatal child health care at County Assembly and National Assembly and The Senate.

\subsection{Foundational Principles}

Clearly, men have an important place in $\mathrm{MNCH}$. This policy, therefore, seeks to harness the potential role that men can play in promoting the health of the mother and child and the importance of strengthening the interface between men and health services for the sake of the mother and child.

o Encourage the involvement of men in program interventions as decision makers, partners and/or health service providers.

o At community level through men's groups, religious organizations, and other community mobilization structures.

There is need to identify the areas and levels of involvement

Counterargument. Be specific on what males: are they husbands, boyfriends, sons, fathers or just any man around?

o Encouraging men to use a Rights approach, citing The Constitution of Kenya 2010, working with local leaders and government-advocacy to hold service providers accountable, interrogating the service charters, memorandum of understanding (MOUs) where there are gaps in health provision,

o Training of community volunteers, retention of as many CHVs as possible volunteering in the program and capacity building. Volunteering cannot be taken for granted or may not be a common concept, so incentives to foster active participation of male community health volunteers were needed. 
Counterargument: The African culture accepts volunteerism but then the community health volunteers have families to feed so need to be paid.

o Targeting men at all levels but especially couples who are expecting a child (see Figure 1).

o Taking a multi sector approach e.g. access to microcredit to ensure domestic economic sustainability. World Vision International recently donated 40 beehives to Chama cha Wazee male champions.

o Ensuring that organizations share their vision with the community to own projects.

o The use of the national media (radio, television, newspapers) as well as local community groups to create awareness and sensitize the general population to $\mathrm{MNCH}$ care and harmful practices. Men listened to the radio a lot more than women.

o Helping men to identify other men who are into drinking, gender based violence, neglecting their families and help them out.

o Identify and create rapport with Boma heads where community units will be established/strengthened. The Boma model has strengthened organizational systems within the community [13].

o Engaging the community with respect.

o Connecting with deep-rooted community structures to ensure sustainability and encourage ongoing grass root involvement of gatekeepers as was cited in [13] above.

o Addressing reproductive health and family planning needs of the male

Counterargument: Most of the available FP methods involve the woman to use not the man. Again, there are sentiments that prevention of mother to child transmission to a large extent concerns the mother and not the father. Since it involves exclusive breast feeding, caesarean section $(\mathrm{C} / \mathrm{s})$ birth, mother taking ARVs prophylactically during pregnancy.

o Policies of health care establishments and attitudes of service providers serve as barriers to greater involvement of men even when they accompany women to health facilities

o Involvement of men in MNCH services would be critical because HIV inci-

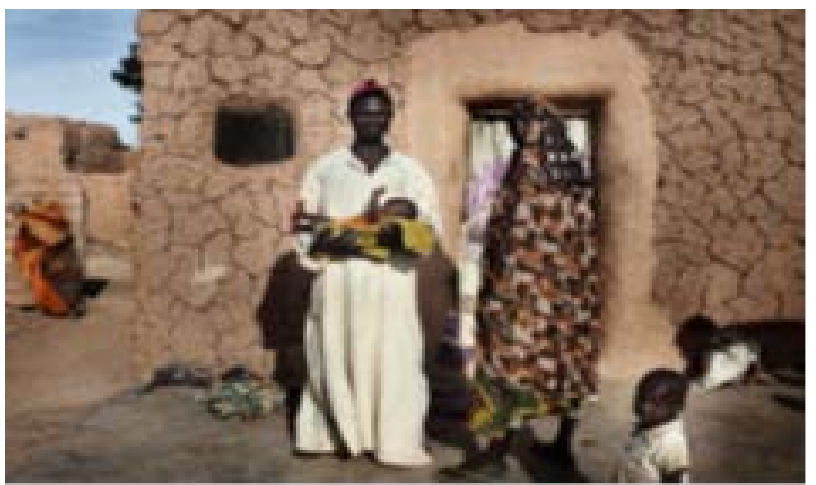

Figure 1. A man holds a baby flanked by his wife and children. (Courtesy of Born Free). 
dences were still high among couples despite available ways of preventing the disease as was cited in [22] above. The study noted that HIV testing of men in ANC did not necessarily result in shared knowledge of HIV status. Nevertheless, in a similar study, partner notification of HIV-1-positive results was reported by 138 women $(64 \%)$ and was associated with a 4 -fold greater likelihood of condom use [23]. We are mostly left with changing our behaviour patterns.

Counterargument: Men are already involved in a big way.

Call to action for men to actively engage in promotion of maternal and new-born health to increase uptake and utilization of services [24]

o Provide male-friendly services that encourage men to accompany their female partners to health facilities and to seek out and use services themselves. Couples who attend clinic are given first priority on the queue [25] [26].

Counterargument: $\mathrm{MCH}$ clinic is for women

o Addressing concerns of men sexual health which have great potential for leading the way in promoting sexual health and efforts to prevent sexually transmitted infections and HIV transmission.

o Encouraging men (those who can) to become individual birth partners of choice during labour.

Counterargument: This cannot happen in the African culture, you cannot expect men in the labour ward.

o Advocate for men as clients, partners, and agents in promoting the uptake of HIV services at family and community level.

o CCW has a vision of starting a 40-bed maternal shelter so that women who are expectant will be near the health facility whenever they might have difficulties accessing care at Meteitei.

Counterargument: Some women might misuse this chance to run away from home, the hostel will be turned into a hospital ward.

\subsection{Elements of Men Entry into the MNCH System}

- $\mathrm{MNCH}$ recognizes the potential role that men play in promoting the health of the mother and child.

- The importance of strengthening the interface between men and health services for the sake of the mother and child.

- Promoting community awareness on infertility (increase access to proper investigation and management of infertile individuals and couples).

- Male involvement in Dialogue Days and other stakeholder forums to reinforce key messages: make maternal health a standing agenda.

- The man helps the woman realize the importance of focussed antenatal care: Early preparation for safe delivery (physiological readiness of the mother, to encompass psychological, intellectual, social and financial preparedness) in order to beat the odds and rise above the contextual challenges.

- By making multiple services available in the same location on a single visit, maximizing on each opportunity for a greater impact. Adopt "One-Stop Shop" approach in the target facility to enable clients' access health services. 
- Men accounting for paternal leave to "shower" care the mother and newborn

- Target men wherever they are with messages on antenatal, hospital delivery, postnatal visits, elimination of mother to child transmission of HIV eMTCT, child welfare, child nutrition and family planning.

- Packaging and repackaging services: integrating family planning with other reproductive health services-postpartum family planning, post abortion contraception, HIV and AIDS services, screening for prevention and control of cancers of reproductive organs in both women and men-namely cancer of the cervix, breast cancer, and prostate cancer.

Counterargument: Men cannot afford to wait.

- The role of the father in supporting breastfeeding; address common myths and misconceptions about breastfeeding. Messaging related to breastfeeding with HIV/AIDS. Men to promote, protect and support mothers to exclusively breastfeed during their infant's first six months. To provide the best local foods from six months through two years of age to help their child grow, develop and survive.

- Sensitize the men on dangers of gender-based violence: physical and sexual abuse and violence, including rape. These are violations of the right to be free from inhumane and degrading treatment? Have long-term negative health impacts, including severe psychological; emotional; and medical consequences, such as the increased risk of unintended pregnancy and sexually transmitted infections, including HIV.

- Men came up with strategies for those women living in inaccessible mountainous areas e.g. a mothers' hostel (maternal shelter) so that they can be near the hospital as their estimated date of delivery nears. A proposal was sent to Nandi County government.

- Facilitate pre-payment schemes: medical insurance, transport to a referral facility through fathers' clubs or other community mechanisms.

Counterargument: Maternity care is free in public hospitals, but the insurance covers the family at all other times.

- Encourage corporate social responsibility. A proposal was sent to George Williamson Tea Company (a major employer in the region) requesting them to equip maternity wing of Meteitei sub-county Hospital with delivery sets, caesarean sets, infant resuscitaires, and delivery beds. Some of these were delivered recently.

- Establishing a partnership with students and faculty who bring students for rural health attachment in the region to identify an intervention project, become alumni's.

- Procure off-road vehicles, trail motorbikes, and ambulance to be stationed, "Beyond zero" campaign truck to be going for outreach in hard to reach zones as was cited in [22] above.

- Advocating for the gradual phasing out of the traditional birth attendant's 
role. One way was by easing the shortage of staff, some who could be able to go and assist the women to deliver in their homes in certain situations.

Counterargument: TBA's play a very important role, culturally acceptable, are friendly, available any time. They have saved many a situation.

- Work with community implementers to record pregnancies and births in the community and plan for outreach

- Emphasis for regular screening for cancer of the breast (clinical and self), prostate cancers (clinical and Prostatic Surface Antigen-PSA tests).

- Highlight special cases like obstetrics fistula, identification, referral and care

- Sexual health and marital counseling.

- Routine community outreach activities, including community health worker home visits, community dialogue sessions, mother support groups, and health action days.

- Distribution of brochures, and posters during home visits, community dialogue sessions, mother support groups, and health action days to support integration efforts, and serve to complement existing community-level reproductive health and nutrition materials.

An antenatal mother who is HIV negative turns positive 6 weeks postnatally during one of the rapid response initiative campaigns. We could conclude that the spouse was HIV positive since they were not tested together or may have been involved in unsafe sex and thus transmitted to the spouse (pregnant woman).

\subsection{Monitoring}

This was how they monitored the activities:

- On a monthly basis, CCW held men focus group discussions to note emerging issues and progress made.

- The number of men groups showcased their initiatives concerning maternal health at county and national level to exchange best practices.

- Acknowledging when the outcome was less than expected.

- Utilization of evidence based tools for probing any maternal neonatal deaths. Modalities on how the membership of the probe teams would be constituted for each facility. Probe team would meet not later than 1 day after such an incident.

- Corrected negative outcomes quickly

- Modified the process to avoid further negative outcomes

- Service charters to note undue delays in waiting time at the facilities

Percentage of men who accompanied their spouse(s) or partner(s)to at least one antenatal care (ANC) visit:(\# of men who accompanied their partner to an ANC visit/ Total \# of women who report their partner had an antenatal visit) $\times 100$.

- Submitted regular performance reports to key administrators like the chief, 
public health officer, and other stakeholders.

- Demonstrated on a regular basis examples of measurement and monitoring e.g. The number of babies immunized (even out of hospital deliveries) within 2 weeks were brought for immunization compared to the number of deliveries per month within the health facility.

Whereas, "Accompany" their partner means that the man went with his spouse or partner to the health facility and ideally was "present" in the room during the ANC check-up.

- Counterargument: these are gender roles that men are not equipped to play

- Submitting regular performance reports to key administrators like the chief, public health officer and other stakeholders.

- Demonstrate on a regular basis examples of measurement and monitoring e.g. The number of babies immunized (even out of hospital deliveries) within 2 weeks were brought for immunization compared to the number of deliveries per month within the health facility.

\section{Discussion}

This paper presents the position of maternal and child health and the involvement of males at Meteitei sub county. The path they had opted to take largely out of their own initiative. The difference it had made in improving maternal, new-born survival suggested that such effort could be replicated throughout the country. Reducing these mortalities could be accelerated in perhaps less than half it had taken since there were now deliberate efforts by various state and non-state actors. Creating policies and laws that supported them should not be taken for granted thus enlightening the leaders was a necessary step. An advocacy approach was found to be one of the effective ways of reaching out. A policy issue to lobby The Senate was a necessary step. It contrasted the diverse arguments and counterarguments.

\section{Summary}

Many male partners would tend to isolate themselves when it reaches a time when a woman is pregnant and also when she gives birth. Ideally, couples should test together at antenatal clinic and retest after every three months. Deal decisively and intervene with any positive results.

With men incorporated Meteitei region showcased that the death of another mother, neonate or child was not excusable. Taking into account the difficult context which includes poverty, lack of access roads to the villages, cultural challenges and personal preferences relating to maternal and child health, Chama cha wazee male champions had considerable influence on the process and outcome of care. Indeed male involvement research is relevant [27] [28], timely and can provide a few answers to reduce infant/child and maternal mortality and eventually translate to stronger families, a healthier and productive/ prosperous nation. 


\section{Acknowledgements}

Chama cha Wazee (CCW) Tinderet, Kenya for allowing us to use their story. CCW has presented their work at various national forums and won several awards for their outstanding contribution.

\section{References}

[1] Martin, D. and Singer, P. (2003) A Strategy to Improve Priority Setting in Health Care Institutions. Health Care Analysis, 11, 59-67. https://doi.org/10.1023/A:1025338013629

[2] Tearfund International. Footsteps No. 93 Edition On-Mobilizing Local Resources Advocacy.

[3] Tearfund International. Footsteps No. 100 Edition On-Creating Positive Change.

[4] Watson, J. (2015) Roots 1 \& 2: Advocacy Toolkits. 2nd Edition. Tearfund International.

[5] Community Tool Box (CTB). http://ctb.ku.edu/en/table-of-contents/advocacy/direct-action/letters-to-elected-offi cials/main

[6] Hagedorn, S. (1995) The Politics of Caring: The Role of Activism in Primary Care. Advances in Nursing Science, 17, 1-11. https://doi.org/10.1097/00012272-199506000-00002

[7] Parker, M. and Smith, M. (2010) Nursing Theories and Nursing Practice. 3rd Edition, Davis, Philadelphia.

[8] Nightingale, F. (1960) Notes on Nursing. What It Is, and What It Is Not. http://digital.library.upenn.edu/women/nightingale/nursing/nursing.html\#II

[9] Nightingale, F. (1894) Sick Nursing and Health Nursing. In: Billings, J. and Hurd, H., Eds., Hospitals, Dispensaries and Nursing. Papers and Discussions in the International Congress of Charities, Correction and Philanthropy, The Johns Hopkins Press, Baltimore.

[10] Wikipedia (2014) Florence Nightingale. http://en.wikipedia.org/wiki/Florence_Nightingale

[11] Kenya Demographic Health Survey KDHS, 2013.

[12] AMREF's Lamu Maternal Newborn \& Child Health Project Video. http://www.Amref.org/info-hub

[13] AMREF (2013) The "BOMA" Health Delivery Model. http://www.amref.org/download/521362a0821a0/

[14] Mangeni, J., Mwangi, A., Mbugua, S. and Mukthar, V. (2013) Male Involvement in Maternal Health Care as a Determinant of Utilization of Skilled Birth Attendants in Kenya. East African Medical Journal, 89, 372-383.

[15] World Vision Kenya (2014) Gaps in Maternal Health Dominate Talks. http://www.wvi.org

[16] Spotlight on Kenya: MCHIP's Integrated Approach to Maternal and Child Health and Nutrition. http://www.mchip.net/print/1353

[17] Mailu, G. (2012) Kenya's MDGs Status Report to Date: Post 2015 MDG Forum. Ministry of Planning, National Development and Vision 2030. https://herafkenya.wordpress.com/2013/05/23/kenyas-health-mdgs-status-report/

[18] CARMMA (Campaign on Accelerated Reduction of Maternal, New-Born and Child 
Mortality in Africa). http://www.carmma.org/scorecard/kenya

[19] K4Health. Division of Reproductive Health Ministry of Health. https://www.k4health.org/toolkits/kenya-h

[20] United Nations Population Fund UNFP (2013) The State of the World's Midwifery.

[21] Born Free. http://www.bornfreeafrica.org

[22] Beyond Zero Campaign. http://www.beyondzero.or.ke/wp-content/uploads/2015/11/Profile-for-the-BeyondZero-Campaign.pdf

[23] Katz, D., Kiarie, J., John-Stewart, G., Richardson, B., John, F. and Farquhar, C. (2009) HIV Testing Men in the Antenatal Setting: Understanding Male NonDisclosure. International Journal of STD AIDS, 20, 765-767.

https://doi.org/10.1258/ijsa.2009.009139

[24] Farquhar, C., Kiarie, J., Richardson, B., Kabura, M., John, F., Nduati, R., Mbori-Ngacha, D. and John-Stewart, G. (2004) Antenatal Couple Counseling Increases Uptake of Interventions to Prevent HIV-1 Transmission. Journal of Acquired Immune Deficiency Syndrome, 37, 1620-1626. https://doi.org/10.1097/00126334-200412150-00016

[25] Office of the First Lady. 2013-2017 Accelerating Progress in Saving the Lives of Women and Children. Government Press, Kenya.

[26] Ministry of Public Health \& Sanitation and Ministry of Health, Kenya (2013) National Guidelines for Quality Obstetrics and Perinatal Care. http://pdf.usaid.gov/pdf_docs/pa00jvxx.pdf

[27] Family Care International (2003) Care-Seeking during Pregnancy, Delivery, and the Postpartum Period: A Study in Homabay and Migori Districts, Kenya. http://www.familycareintl.org/UserFiles/File/SCI\%20Kenya\%20qualitative\%20repor t.pdf

[28] Hendriks, S., Mkandawire, E. and Mkandawire-Valhmu, L. (2016) When Men Tackle Mother and Child Health: Lessons from Malawi. The Conversation. https://theconversation.com/when-men-tackle-mother-and-child-health-1

Submit or recommend next manuscript to OALib Journal and we will provide best service for you:

- Publication frequency: Monthly

- 9 subject areas of science, technology and medicine

- Fair and rigorous peer-review system

- Fast publication process

- Article promotion in various social networking sites (LinkedIn, Facebook, Twitter, etc.)

- Maximum dissemination of your research work

Submit Your Paper Online: Click Here to Submit

Or Contact service@oalib.com 